\title{
BOMBAY LEPROSY PROJECT
}

Bombay Leprosy Project (BLP) sponsored by the German Leprosy Relief Association (GLRA) started work in October 1976 with the object of establishing a model for urban leprosy control in India. Similar projects of GLRA, are in operation in two other major cities in the country namely Madras and Calcutta.

Earlier experience gained through extensive school surveys in Bombay (Ganapati, R. et al., Lepr. Rev. 47, 127-131, 1976) had indicated the existence of pockets of high prevalence of leprosy in some northern suburbs of the city, presumably of the order of $10-15$ per thousand especially in the slums, where more than a third of the city's population ( 7 millions according to mid-year estimation in 1976) reside under very poor hygienic conditions. No studies on overall prevalence rate for the city are available.

The area chosen by the project for intensive control work is about 16 square kilometers in extent and the population at risk is approximately 325,000 . The control work of three other units receiving financial aid from the GLRA and operating with uniform methodology in adjoining areas covering a total population of 1.5 million is also coordinated by the BLP so that after a few years of work, it is hoped that epidemiologically useful data on a large section of urban population would be available.

Since January, 1977, when the actual field work gained momentum, 35,089 slum dwellers (out of the enumerated population of 51,089 ) and 40,689 school children (out of 49,478 on roll) have been examined up to the end of July 1978. Health education has resulted in ensuring reasonably regular treatment of patients reporting voluntarily at a number of treatment centres started in the slums. So far 887 patients have been detected, out of whom 772 (10.1\% lepromatous) are registered for standard treatment with DDS. Clofazimine and rifampicin are used in special situations and not as a measure to contain the infection in the community. Prednisolone and thalidomide are employed to treat reactions.

The finding of major importance so far has been the confirmation of the existence of hyperendemic slum foci. In one closely packed community of 3812 subjects, screening of 3178 members unearthed 10 proved smearpositive cases, which alone works out to a prevalence rate of 3.1 per 1000 (total prevalence rate including cases of lesser public health significance being 
24.8 per 1000). It is by no means conclusive that a similar situation exists in all the slums. Our experience in the limited number of slums which we have surveyed so far indicates that by the standards recommended by the WHO, virtually the entire population of the project area must be regarded as exposed.

Though the prevalence of dapsone resistance has not been established by laboratory methods, the existence of persistently smear-positive patients treated irregularly earlier, and relapsing with characteristic lesions indicates this possibility, which not only enhances the risk to the exposed population but poses therapeutic problems.

Studies of population movement into and out of the area chosen for control have not been carried out and preliminary work suggests that the majority of the population in slums, especially those situated along the coastline, is quite stable.

R. GANAPATI 